\title{
Efeito da temperatura ambiente e da idade do frango sobre o valor energético do farelo de soja
}

\author{
[Effects of environmental temperature and age of broilers on energy value of soybean meal]
}

\author{
F.B. Carvalho ${ }^{1}$, J.R. Sartori ${ }^{1}$, J. H. Stringhini ${ }^{2}$, V.B. Fascina ${ }^{1}$, L.A. Pereira ${ }^{1}$, V.C. Pelícia ${ }^{1}$
}

${ }^{1}$ Departamento de Melhoramento e Nutrição Animal - FMVZ-UNESP - Botucatu, SP

${ }^{2}$ Departamento de Produção Animal - Escola de Veterinária - UFG - Goiânia, GO

\begin{abstract}
RESUMO
Foram utilizados 288 pintos de corte Cobb, distribuídos em delineamento experimental inteiramente ao acaso, em esquema de parcelas subdivididas no tempo, sendo as três temperaturas de criação - fria, termoneutra e quente - as parcelas, e as três fases de avaliação - inicial, crescimento e final - as subparcelas, com seis repetições de seis aves cada. A dieta-teste foi obtida pela substituição de parte da ração basal pelo alimentoteste: $40 \%$ do farelo de soja $+60 \%$ da ração basal. Foram calculados os coeficientes de metabolizabilidade aparente e verdadeiro da matéria seca, do nitrogênio, do extrato etéreo da dieta-teste e os valores de energia metabolizável aparente e verdadeira (EMA e EMV), e corrigidas pelo balanço de nitrogênio do farelo de soja (EMAn e EMVn). Foram encontrados valores médios de EMAn do farelo de soja para aves criadas em temperatura fria, termoneutra e quente de 2110,2016 e $2022 \mathrm{kcal} / \mathrm{kg}$, respectivamente, e para as fases de criação inicial, crescimento e final de 1840, 2052 e $2256 \mathrm{kcal} / \mathrm{kg}$, respectivamente. O valor de energia metabolizável do farelo de soja, os balanços e os coeficientes de metabolizabilidade dos nutrientes da dieta-teste aumentaram com a idade do frango de corte, porém não são afetados pela temperatura ambiente.
\end{abstract}

Palavras-chave: frango de corte, balanço de nitrogênio, energia metabolizável, idade, temperatura ambiente

\begin{abstract}
Two hundred and eighty-eight Cobb chicks were distributed in a completely randomized design with a splitplot arrangement with six replication of six chicks each, the main plots were in three temperatures (cold, thermo neutral and hot) and the secondary plot were by phase (initial, growing and final). The test diet was produced by replacing the basal diet with test food: $40 \%$ soybean meal $+60 \%$ basal diet. The coefficient of apparent and true metabolizability of dry matter, nitrogen, ether extract of the test diet and apparent and true metabolizable energies (AME and TME) of soybean meal were calculated and energy values were corrected for nitrogen balance (AMEn and TMEn) of soybean meal, in kcal/kg, as fed basis. The mean values of AMEn observed for broiler chicks in cold, thermo neutral and hot temperature were 2110, 2016 and $2022 \mathrm{kcal} / \mathrm{kg}$, respectively, and the initial, growing and final phases were 1840, 2052 and $2256 \mathrm{kcal} / \mathrm{kg}$, respectively. The metabolizable energy values of soybean meal, the balance and coefficients of metabolizability of the nutrients of the test diet increased with the age of broiler; however, they were not affected by environmental temperature.
\end{abstract}

Keywords: broiler, nitrogen balance, metabolizable energy, age, environmental temperature

\section{INTRODUÇÃO}

$\mathrm{Na}$ formulação de dietas, a composição dos ingredientes e seus respectivos valores energéticos devem ser os mais exatos possíveis, justificando a determinação da composição química e dos valores de energia metabolizável dos alimentos nacionais comumente utilizados nas formulações. Sabe-se que existem variações nas composições dos alimentos, pois regiões geográficas, condições de plantio, fertilidade de solo, variabilidade genética dos cultivares, formas de armazenamento e processamento dos grãos vegetais são fatores que influenciam nos

Recebido em 6 de outubro de 2010

Aceito em 11 de agosto de 2011

E-mail: fabyolab@hotmail.com 
valores nutricionais dos alimentos. Além das variações na composição dos alimentos, existem também variações na forma de utilização desses alimentos pelo frango de corte, as quais são alteradas em virtude do melhoramento genético, da idade da ave, do sexo, da linhagem e da temperatura ambiente.

A soja na forma de grãos ou farelo é destacada na literatura como importante matéria prima na formulação de rações, devido ao seu elevado valor nutritivo. De acordo com Dale (1997), vários estudos vêm sendo realizados visando obter um máximo aproveitamento de suas propriedades nutricionais, já que, na maioria das vezes, o farelo de soja é responsável por aproximadamente $70 \%$ da suplementação proteica nas rações. $\mathrm{O}$ farelo de soja possui cerca de $5 \%$ mais energia bruta que o milho, no entanto a energia metabolizável (EM) é aproximadamente 87\% da EM do milho (Bellaver e Snizek Jr., 1999).

Em geral, as recomendações sobre nutrição e alimentação de frangos de corte são realizadas em temperatura ambiente dentro da faixa de conforto das aves em crescimento, não sendo adequadas para atender as exigências energéticas das aves em ambiente de estresse por calor ou frio, podendo ser uma das causas do declínio de desempenho de frangos de corte. O estresse térmico influencia a produtividade dos animais por alterar sua troca de calor com o meio, modificando o consumo do alimento, o ganho de peso corporal e, consequentemente, a metabolizabilidade dos nutrientes. Considerando que as aves reduzem voluntariamente o consumo de alimento, à medida que a temperatura ambiente se eleva acima da faixa de conforto térmico, uma ração formulada para condições de termoneutralidade não seria adequada para atender as exigências energéticas das aves em ambiente de estresse por calor (Oliveira et al., 2000).

Os programas de alimentação para frangos de corte têm evoluído muito nos últimos anos, com a finalidade de melhor associar a nutrição com a fisiologia da ave moderna. A determinação semanal dos valores de energia metabolizável dos ingredientes pode contribuir para a adequação calórica das rações. Sabe-se que, à medida que avança a idade das aves, há um aumento da capacidade digestiva, ocorrendo aumento do aproveitamento dos nutrientes em função do desenvolvimento dos órgãos acessórios e do próprio sistema digestório, portanto a formulação utilizando os valores de energia metabolizável do alimento ajustados para a idade da ave pode significar maior otimização na formulação e menos desperdício de nutrientes na ração, obtendo melhora na conversão alimentar, consequentemente, diminuição no custo alimentar.

Considerando os fatores abordados, o presente estudo teve por objetivo determinar o efeito da temperatura ambiente e da idade da ave sobre o valor energético do farelo de soja.

\section{MATERIAL E MÉTODOS}

Foram utilizados 288 pintos de corte machos da linhagem $\mathrm{Cobb}$, dos quais 216 foram distribuídos em 36 gaiolas de arame galvanizado, medindo $0,50 \mathrm{~m}$ de altura, $0,50 \mathrm{~m}$ de largura e $0,60 \mathrm{~m}$ de profundidade, distribuídos em três câmaras climatizadas - quente, termoneutra e fria -, sendo as gaiolas dispostas em duas baterias de dois andares cada, perfazendo um total de 12 gaiolas/câmara. Os 72 pintinhos restantes foram empregados em tratamento extra - jejum por $72 \mathrm{~h}$ - para avaliar as perdas endógenas e metabólicas em cada idade de avaliação dentro das três câmaras climáticas, de modo a determinar o fator de correção para estimar a energia metabolizável verdadeira do farelo de soja (Sakomura e Rostagno, 2007).

A dieta basal foi formulada à base de milho e farelo de soja, e a composição dos alimentos e as exigências nutricionais foram obtidas a partir de Rostagno et al. (2005). A dieta-teste foi obtida por substituição de parte da ração basal pelo alimento-teste: $40 \%$ do farelo de soja $+60 \%$ da ração basal. A composição da ração basal nas diferentes fases de criação está apresentada na Tab. 1.

O delineamento experimental foi inteiramente ao acaso, com esquema de parcelas subdivididas no tempo, sendo as três temperaturas - fria: $18^{\circ} \mathrm{C}$, termoneutra: $25^{\circ} \mathrm{C}$ e quente: $33^{\circ} \mathrm{C}$ - as parcelas, e as três idades de avaliação - inicial: 11 a 14 , crescimento: 25 a 28 e final: 39 a 42 dias - as subparcelas, com seis repetições de seis aves. 
Todas as aves permaneceram na câmara quente até os seis dias de idade para não comprometer seu desempenho inicial. Posteriormente, foram distribuídas aleatoriamente nas três câmaras. Foram realizados três ensaios metabólicos constituídos de quatro dias de coleta, utilizandose o método de coleta total das excretas. As excretas foram recolhidas duas vezes ao dia ( $8 \mathrm{~h} \mathrm{e}$ 17h), acondicionadas em sacos plásticos, identificadas por repetição e armazenadas em freezer. Ao final de cada ensaio metabólico, foi determinada a quantidade de ração consumida, bem como a quantidade total das excretas produzidas.
As amostras de ração e excretas foram armazenadas em ambiente refrigerado $\left(-16^{\circ} \mathrm{C}\right)$ para posterior análise de matéria seca (MS), nitrogênio $(\mathrm{N})$, extrato etéreo (EE) segundo metodologia descrita por Silva e Queiroz (2002). Com base nesses resultados, foram calculados os balanços de nitrogênio $(\mathrm{BN})$ e de extrato etéreo (BEE), bem como os coeficientes de metabolizabilidade aparente e verdadeiro da matéria seca (CMMS, CMMSV), do extrato etéreo e (CMEE, CMEEV) do nitrogênio (CMN,CMNV) da dieta-teste.

Tabela 1. Composição e valores calculados das rações experimentais

\begin{tabular}{|c|c|c|c|c|}
\hline \multirow[b]{2}{*}{ Ingrediente } & \multicolumn{4}{|c|}{ Fases de criação (dias de idade) } \\
\hline & 1 a 7 & 8 a 21 & 22 a 35 & 36 a 42 \\
\hline Milho & 61,175 & 64,910 & 66,600 & 70,600 \\
\hline Farelo de soja & 28,300 & 24,710 & 18,000 & 14,520 \\
\hline Farinha de carne & 2,000 & 2,500 & 5,500 & 5,500 \\
\hline Sal comum & 0,240 & 0,220 & 0,170 & 0,160 \\
\hline Supl. vitamínico e mineral & $0,500^{1}$ & $0,400^{1}$ & $0,400^{2}$ & $0,200^{3}$ \\
\hline Calcário calcítico & 0,800 & 0,750 & 0,450 & 0,395 \\
\hline Fosfato bicálcico & 1,450 & 1,150 & 0,250 & 0,120 \\
\hline DL-metionina & 0,185 & 0,130 & 0,130 & 0,130 \\
\hline L-lisina & 0,510 & 0,370 & 0,420 & 0,455 \\
\hline Protenose & 4,500 & 4,510 & 4,770 & 4,700 \\
\hline Bicarbonato de sódio & 0,340 & 0,350 & 0,310 & 0,290 \\
\hline Amido & & & 3,000 & 3,130 \\
\hline Total & 100,000 & 100,000 & 100,000 & 100,000 \\
\hline \multicolumn{5}{|l|}{ Valores calculados } \\
\hline EM (kcal/kg) & 2950 & 3000 & 3099 & 3152 \\
\hline $\mathrm{PB}(\%)$ & 22,04 & 20,79 & 19,42 & 18,55 \\
\hline Cálcio $(\%)$ & 0,94 & 0,89 & 0,82 & 0,76 \\
\hline Fósforo disponível (\%) & 0,47 & 0,44 & 0,41 & 0,38 \\
\hline Metionina $(\%)$ & 0,52 & 0,48 & 0,43 & 0,41 \\
\hline Metionina + cistina $(\%)$ & 0,82 & 0,74 & 0,70 & 0,67 \\
\hline Lisina $(\%)$ & 1,33 & 1,14 & 1,07 & 1,02 \\
\hline Treonina (\%) & 0,72 & 0,68 & 0,62 & 0,57 \\
\hline Potássio (\%) & 0,73 & 0,69 & 0,61 & 0,56 \\
\hline Sódio $(\%)$ & 0,22 & 0,22 & 0,21 & 0,20 \\
\hline Cloro $(\%)$ & 0,20 & 0,19 & 0,18 & 0,17 \\
\hline Ácido linoleico (\%) & 1,38 & 1,43 & 1,42 & 1,46 \\
\hline
\end{tabular}

${ }^{1}$ Suplemento vitamínico e mineral Vaccinar Nutrição e Saúde Animal (por kg de ração): ácido fólico 1,25mg, ácido pantotênico $12,5 \mathrm{mg}$, B.H.T. $2,5 \mathrm{mg}$, biotina $0,125 \mathrm{mg}$, cobre $12,5 \mathrm{mg}$, colina $750,0 \mathrm{mg}$, ferro $62,62 \mathrm{mg}$, iodo $0,025 \mathrm{mg}$, manganês $67,5 \mathrm{mg}$, niacina 37,5mg, selênio $0,225 \mathrm{mg}$, vitamina A $12.500 \mathrm{UI}$, vitamina B1 2,5mg, vitamina B12 25mg, vitamina B2 5,0mg, vitamina B6 5,0mg, vitamina D3 2.500 UI, vitamina E 25,0mg, vitamina K3 2,5mg, zinco 68,75mg, avilamicina $7,5 \mathrm{mg}$, monensina $125,0 \mathrm{mg}$.

${ }^{2}$ Suplemento vitamínico e mineral Vaccinar Nutrição e Saúde Animal (por kg de ração): ácido fólico 1,0mg, ácido pantotênico 10,0mg, B.H.T. 2,0mg, biotina $0,1 \mathrm{mg}$, cobre $10,0 \mathrm{mg}$, colina $600,0 \mathrm{mg}$, ferro $50,1 \mathrm{mg}$, iodo $0,02 \mathrm{mg}$, manganês $54,0 \mathrm{mg}$, niacina 30,0mg, selênio $0,18 \mathrm{mg}$, vitamina A 10.000 UI, vitamina B1 2,0mg, vitamina B12 20,0mg, vitamina B2 4,0mg, vitamina B6 4,0mg, vitamina D3 2.000 UI, vitamina E 20,0mg, vitamina K3 2,0mg, zinco 55,0mg, avilamicina $6,0 \mathrm{mg}$, monensina 100,0mg.

${ }^{3}$ Suplemento vitamínico e mineral Vaccinar Nutrição e Saúde Animal (por kg de ração): ácido fólico 0,5mg, ácido pantotênico $5,0 \mathrm{mg}$, B.H.T. $1,0 \mathrm{mg}$, biotina $0,05 \mathrm{mg}$, cobre $5,0 \mathrm{mg}$, colina $300,0 \mathrm{mg}$, ferro $25,05 \mathrm{mg}$, iodo $0,01 \mathrm{mg}$, manganês $27,0 \mathrm{mg}$, niacina $15,0 \mathrm{mg}$, selênio $0,09 \mathrm{mg}$, vitamina A 5.000 UI, vitamina B1 $1,0 \mathrm{mg}$, vitamina B12 10,0mg, vitamina B2 2,0mg, vitamina B6 2,0mg, vitamina D3 $1.000 \mathrm{UI}$, vitamina E 10,0mg, vitamina K3 1,0mg, zinco 27,5mg, avilamicina $3,0 \mathrm{mg}$, monensina $50,0 \mathrm{mg}$. 
Para obtenção dos valores de energia bruta das dietas e excretas, foi utilizada a bomba calorimétrica (Ika Works modelo C-200) e, a partir desses resultados, foram calculadas as energias metabolizável aparente e verdadeira (EMA e EMV), e corrigidas pelo balanço de nitrogênio (EMAn e EMVn) utilizando-se as equações propostas por Matterson et al. (1965).

As análises estatísticas foram realizadas por meio de análise de variância com o auxílio do SAEG (Sistema..., 2007). Para verificar diferenças significativas entre as médias dos tratamentos, foi utilizado o teste de Tukey $(5 \%$ de probabilidade).

\section{RESULTADOS E DISCUSSÃO}

A composição química do farelo de soja na matéria natural utilizado no experimento foi: $87,9 \%$ de matéria seca, $44,7 \%$ de proteína bruta, $1,6 \%$ de extrato etéreo e $4146 \mathrm{kcal} / \mathrm{kg}$ de energia bruta. O valor de proteína obtido para o farelo de soja foi mais alto que o dos cinco farelos avaliados por Zonta et al. (2004), de 41,6 a $44,3 \%$, e mais baixo que os apresentado por Rostagno et al. (2005), de 45,3\%. Segundo Mello et al. (2009), os farelos de soja de origens diversas podem diferir quanto ao teor de casca, o que interfere nos valores de PB e fibra deste alimento. Penz Jr. et al. (2009) mostraram resultado de pesquisa realizada em um banco de dados de uma empresa no período de 2005 a 2009, em que foram analisadas 16.896 amostras de farelo de soja, e encontraram média de 46,1\% de proteína bruta com coeficiente de variação de $2,6 \%$.

Não houve efeito da interação temperatura ambiente versus idade da ave (Tab. 2) para as energias metabolizáveis. A temperatura ambiente como efeito isolado também não interferiu nos resultados encontrados.

A alta porcentagem de proteína bruta encontrada na dieta teste do farelo de soja (média de $28 \%$ de PB) poderia, juntamente ao calor já existente sob condições de alta temperatura, ter causado aumento no estresse, pois, segundo McLeod (1997), a degradação do excesso de aminoácidos (proteína) da dieta produz alto incremento calórico. Esse efeito do excesso de aminoácidos no trabalho atual não causou maior estresse para as aves criadas na câmara quente, mas pode ter auxiliado as aves a manterem a homeotermia na câmara fria, apresentando maiores valores para as energias metabolizáveis do farelo de soja (sem diferença estatística) na câmara fria (média de $3,7 \%$ ).

Tabela 2. Valores de energia metabolizável aparente (EMA), verdadeira (EMV) e corrigidas pelo balanço de nitrogênio (EMAn, EMVn) do farelo de soja (kcal/kg) expressos na matéria natural, determinados em frangos de corte nas fases inicial, crescimento e final, criados em câmaras climáticas

\begin{tabular}{lcccc} 
& EMA & EMAn & EMV & EMVn \\
\cline { 2 - 5 } & \multicolumn{4}{c}{ Câmara } \\
\hline Fria & 2240 & 2110 & 2435 & 2259 \\
Termoneutra & 2179 & 2016 & 2377 & 2118 \\
Quente & 2155 & 2022 & 2358 & 2176 \\
& & Fase & & \\
Inicial & $2001 \mathrm{c}$ & $1840 \mathrm{c}$ & $2136 \mathrm{~b}$ & $1951 \mathrm{~b}$ \\
Crescimento & $2208 \mathrm{~b}$ & $2052 \mathrm{~b}$ & $2468 \mathrm{a}$ & $2201 \mathrm{a}$ \\
Final & $2365 \mathrm{a}$ & $2256 \mathrm{a}$ & $2565 \mathrm{a}$ & $2400 \mathrm{a}$ \\
& & & $\mathrm{ns}$ \\
Câmara (C) & $\mathrm{ns}$ & $\mathrm{ns}$ & 0,001 & 0,001 \\
Fase (F) & 0,001 & 0,001 & $\mathrm{~ns}$ & $\mathrm{~ns}$ \\
C x F & $\mathrm{ns}$ & $\mathrm{ns}$ & 5,30 & 9,06 \\
CV (\%) & 4,75 & 5,58 & $\mathrm{~ns}$ \\
\hline
\end{tabular}

Letras diferentes na coluna indicam diferenças entre valores pelo teste de Tukey (5\%).

No entanto, Faria Filho et al. (2007) avaliaram efeito da temperatura ambiente $\left(22\right.$ e $\left.32^{\circ} \mathrm{C}\right)$ e aumento de proteína bruta na dieta $(17,20$ e $23 \%$ ) sobre o metabolismo e o desempenho de frangos de 21 a 42 dias de idade. Os autores não encontraram efeito da temperatura ambiente sobre o metabolismo da ave, mas os coeficientes de metabolização da matéria seca, proteína e a 
EMAn diminuíram com o aumento do teor de proteína bruta da ração.

Geraert et al. (1992) e Piva (2008) também verificaram que o teor de energia metabolizável da dieta não foi alterado pela exposição de frangos ao calor, enquanto Keshavarz e Fuller (1980) observaram teores mais elevados, e Yamazaki e Zi-Yi (1982) teores mais baixos de energia em galos Legorhns de 12 meses de idade. Essas diferenças nos resultados podem ser atribuídas às condições experimentais específicas de cada estudo, como linhagem, níveis nutricionais, ingredientes utilizados, sexo, período de avaliação (idade), entre outros.

Aves na fase final apresentaram maior $(\mathrm{P}<0,05)$ EMA e EMAn que nas demais fases de criação (Tab. 2). Quando foram retiradas as perdas endógenas e calculada a energia metabolizável verdadeira do farelo de soja, os maiores valores se mantiveram para aves na fase final $(\mathrm{P}<0,05)$, não diferindo da fase de crescimento. Este resultado pode estar relacionado com a maturação do trato gastrintestinal que, segundo Uni et al. (1998), estabelece-se aos 16 dias de idade em frangos de corte.

Sakomura et al. (2004) verificaram aumento linear da atividade da amilase, da tripsina e da lipase com o avançar da idade da ave (um a sete; oito a $14 ; 15$ a 21 e 22 a 28 dias). A fase de maior aumento ocorreu entre a primeira e a segunda semana de idade, coincidindo com o máximo crescimento alométrico do pâncreas. As rápidas alterações do trato digestório possibilitam aumento de consumo de ração, alterando a digestibilidade dos nutrientes.

Ao pesquisarem o efeito da idade da ave sobre o valor da energia metabolizável de alimentos de origem vegetal, Generoso et al. (2008) observaram que valores médios de energia metabolizável aparente corrigida pelo balanço de nitrogênio do farelo de soja, determinados com frangos de corte nos períodos de crescimento 21 a 30 dias de idade - e final - 41 a 50 dias -, aumentaram com o avanço da idade, de 2020 para $2306 \mathrm{kcal} / \mathrm{kg}$ na matéria natural, respectivamente. No presente trabalho atual, o aumento na EMAn de aves dos 14 dias para 42 dias de idade foi em torno de $18,4 \%$.
Os resultados de EMAn e EMVn do farelo de soja foram mais baixos que os apresentados pelas Tabelas Brasileiras para Aves e Suínos (Rostagno et al., 2005), 2256 e $2486 \mathrm{kcal} / \mathrm{kg}$ na $\mathrm{MN}$, respectivamente, com exceção das aves na fase final, $2256 \mathrm{kcal} / \mathrm{kg}$, para EMAn. Importante ressaltar que os valores apresentados por Rostagno et al. (2005) são compilações de trabalhos com frangos de corte em diferentes idades, galos e poedeiras. Como é comum utilizar a EMAn para formulação de ração, segundo os resultados deste trabalho, em todas as temperaturas utilizadas, os valores foram mais baixos que os apresentados na tabela de Rostagno et al. (2005). Esse valor superestimado na formulação da ração pode causar redução no desempenho dessas aves.

Alguns trabalhos avaliaram o valor energético do farelo de soja e encontraram valores de 2512 e $2577 \mathrm{kcal} / \mathrm{kg}$ de EMAn e EMVn, respectivamente, na matéria natural (Nascimento et al., 1998) e valores de 2171 a $2473 \mathrm{kcal} / \mathrm{kg}$ de EMAn na matéria natural (Zonta et al., 2004).

Não houve efeito da interação temperatura ambiente versus idade da ave para os balanços de nitrogênio e extrato etéreo (Tab. 3). O balanço de nitrogênio verdadeiro foi influenciado pela temperatura ambiente e pela idade da ave de forma isolada. Aves criadas em temperatura fria e termoneutra utilizaram melhor o nitrogênio da dieta-teste que aves criadas em estresse por calor $(\mathrm{P}<0,05)$.

Zuprizal et al. (1993) inferiram que a metabolização da proteína é reduzida pelo calor independentemente do sexo e da dieta. Aves expostas ao calor apresentaram maior consumo de água (Bonnet et al., 1997; Faria Filho, 2006), o que pode causar menor digestibilidade dos nutrientes por aumentar a taxa de passagem da ração. O calor também é responsável por reduzir o tamanho de órgãos (Furlan et al., 2001) e da superfície das vilosidades intestinais (Marchini et al., 2009). No presente trabalho, essa redução voluntária de consumo de aves em temperatura quente pode ter causado a redução na retenção do nitrogênio na câmara quente. 
Tabela 3. Valores de balanço de nitrogênio e de extrato etéreo aparente (BN e BEE) e verdadeiro (BNV e $\mathrm{BEEV})$ da dieta-teste, determinados em frangos de corte nas fases inicial, crescimento e final, criados em câmaras climáticas

\begin{tabular}{|c|c|c|c|c|}
\hline & $\mathrm{BN}(\mathrm{g})$ & BNV (g) & $\mathrm{BEE}(\mathrm{g})$ & $\operatorname{BEEV}(\mathrm{g})$ \\
\hline \multicolumn{5}{|c|}{ Câmara } \\
\hline Fria & 24,40 & $35,10 \mathrm{a}$ & 36,43 & 39,49 \\
\hline Termoneutra & 26,43 & $35,96 a$ & 35,00 & 37,80 \\
\hline Quente & 18,84 & $25,56 \mathrm{~b}$ & 28,51 & 30,43 \\
\hline \multicolumn{5}{|c|}{ Fase } \\
\hline Inicial & 17,65 & $21,34 \mathrm{c}$ & $19,73 b$ & $20,65 b$ \\
\hline Crescimento & 29,25 & $42,32 \mathrm{a}$ & $40,35 \mathrm{a}$ & $44,22 \mathrm{a}$ \\
\hline Final & 22,77 & $32.96 b$ & $40,21 \mathrm{a}$ & $42,86 a$ \\
\hline Câmara (C) & $\mathrm{ns}$ & 0,001 & ns & ns \\
\hline Fase $(F)$ & ns & 0,001 & 0,001 & 0,001 \\
\hline $\mathrm{C} \times \mathrm{F}$ & ns & ns & ns & ns \\
\hline $\mathrm{CV}^{1}(\%)$ & 26,26 & 18,94 & 9,42 & 8,77 \\
\hline
\end{tabular}

Letras diferentes na coluna indicam diferenças entre valores pelo teste de Tukey (5\%).

Aves na fase de crescimento apresentaram melhor balanço de nitrogênio verdadeiro $(\mathrm{P}<0,05)$ que as de outras idades. As proteínas são fundamentais no aspecto nutricional $\mathrm{e}$ metabólico para o frango de corte, pois estão relacionadas a processos do organismo, como a formação dos tecidos estruturais (músculo). Por exemplo, nos animais em crescimento, a deposição proteica nos músculos esqueléticos contribui com cerca de $65 \%$ de toda a proteína depositada diariamente (Rutz, 2002).

Apenas a idade da ave influenciou os balanços de extrato etéreo aparente e verdadeiro $(\mathrm{P}<0,05)$. Aves na fase inicial aproveitaram menos 0 extrato etéreo que aves nas fases de crescimento e final. $\mathrm{Na}$ ave jovem, a presença de substrato parece induzir maior produção de enzimas no trato digestório. Sendo assim, a atividade das enzimas digestivas, tanto pancreáticas como de membrana, aumenta com a idade da ave, atingindo níveis mais elevados, em média, aos 10 dias de idade em frangos de corte (Noy e Sklan, 1997). As rápidas alterações do trato digestório possibilitam aumento de consumo de ração e alteram a digestibilidade dos nutrientes. $\mathrm{O}$ maior balanço de extrato etéreo obtido com aves na fase final se deve provavelmente à maior produção de enzimas para digestão de lipídios dessas aves em relação às aves jovens.

Foram calculados os coeficientes de metabolizabilidade aparente e verdadeiro da matéria seca, nitrogênio e extrato etéreo (Tab. 4). O CMMS da dieta teste foi reduzido com o estresse por calor e aumentou com o avançar da idade $(\mathrm{P}<0,05)$. Esse resultado mostra que tanto a matéria seca como a energia metabolizável (Tab. 2, sem diferença estatística) e o BNV (Tab. 3) foram bem utilizados em temperatura fria. Ao se retirarem as perdas endógenas (CMMSV), o efeito de temperatura ambiente não se manteve, mas aves na fase final continuaram utilizando melhor a matéria seca $(\mathrm{P}<0,05)$, não diferindo da fase de crescimento.

Kato (2005) avaliou o consumo de ração e o tempo de passagem das dietas-testes, com $40 \%$ de milho, $30 \%$ de farelo de soja e $10 \%$ de óleo de soja para frangos de corte. $\mathrm{O}$ autor observou que de um a sete, oito a 14 e 15 a 21 dias de idade o tempo de passagem das rações teste, tanto do farelo de soja como do óleo de soja, foi menor que do milho. Não foi avaliada esta característica no atual trabalho, mas essa alta taxa de passagem para a dieta com $30 \%$ de farelo de soja pode ter ocorrido neste trabalho também, principalmente para aves em estresse por calor que reduzem o consumo voluntariamente, ocasionando a redução no CMMS

Outro ponto é que dietas com alto teor proteico apresentam alta concentração em potássio, em razão da maior inclusão de farelo de soja que é um ingrediente rico nesse mineral. Essas dietas podem estimular o consumo de água, como mostrou o resultado de Faria Filho (2006), no qual o aumento do teor proteico da ração estimulou progressivamente o consumo de água dos frangos de corte. 
Efeito da temperatura ambiente...

Tabela 4. Valores (\%) de coeficiente de metabolizabilidade aparente da matéria seca, do nitrogênio, do extrato etéreo (CMMS, CMN e CMEE) e verdadeiro (CMMSV, CMNV e CMEEV) da dieta teste, determinados em frangos de corte nas fases inicial, crescimento e final, criados em câmaras climáticas

\begin{tabular}{lcccccc}
\hline & CMMS & CMMSV & CMN & CMNV & CMEE & CMEEV \\
\cline { 2 - 7 } & \multicolumn{7}{c}{ Câmara } \\
\hline Fria & $61,62 \mathrm{a}$ & 69,93 & 33,63 & 48,09 & 83,13 & 89,00 \\
Termoneutra & $61,88 \mathrm{a}$ & 71,69 & 38,78 & 52,12 & 80,45 & 86,32 \\
Quente & $60,84 \mathrm{~b}$ & 70,31 & 34,26 & 46,10 & 79,10 & 82,41 \\
\cline { 2 - 7 } & \multicolumn{7}{c}{ Fase } \\
Inicial & $59,04 \mathrm{c}$ & $65,85 \mathrm{~b}$ & 35,81 & 43,33 & 78,72 & 86,90 \\
Crescimento & $61,48 \mathrm{~b}$ & $72,88 \mathrm{a}$ & 36,50 & 52,92 & 79,33 & 90,23 \\
Final & $63,82 \mathrm{a}$ & $73,20 \mathrm{a}$ & 34,35 & 50,06 & 84,63 & 83,59 \\
& & & & & \\
Câmara (C) & 0,001 & $\mathrm{~ns}$ & $\mathrm{~ns}$ & 0,017 & $\mathrm{~ns}$ & $\mathrm{~ns}$ \\
Fase (F) & 0,001 & 0,001 & $\mathrm{~ns}$ & 0,001 & $\mathrm{~ns}$ & $\mathrm{~ns}$ \\
C x F & $\mathrm{ns}$ & $\mathrm{ns}$ & $\mathrm{ns}$ & 0,013 & $\mathrm{~ns}$ & $\mathrm{~ns}$ \\
CV (\%) & 1,55 & 3,92 & 14,78 & 9,28 & 2,80 & 3,01 \\
\hline
\end{tabular}

Letras diferentes na coluna indicam diferenças entre valores pelo teste de Tukey (5\%).

Freitas et al. (2005) encontraram maior EMAn e digestibilidade da matéria seca aparente do farelo de soja reconstituído com óleo de soja para aves adultas (galos com 85 semanas de idade), quando comparados a pintos de 12 a 21 dias de idade. Isso se deve à maior capacidade digestiva dessas aves em relação às aves jovens. No mesmo estudo, não houve variações nos resultados de digestibilidade aparente do extrato etéreo para as duas idades.

A metabolização do nitrogênio e do extrato etéreo aparente e verdadeiro não demonstrou influência da temperatura e da idade das aves (Tab. 4), diferentemente dos resultados de Sakomura et al. (2004), que encontraram aumento da digestibilidade aparente e verdadeira do extrato etéreo para a mistura de farelo de soja e óleo de soja até a terceira semana de idade de frangos de corte.
Houve efeito da interação temperatura ambiente versus idade da ave para CMNV (Tab. 5). A temperatura não influenciou o CMNV das aves na fase inicial, porém, na fase de crescimento, aves criadas em temperatura fria e termoneutra obtiveram os melhores CMNV $(\mathrm{P}<0,05)$; já na fase final, apenas aves em conforto térmico apresentaram os melhores coeficientes. Faria Filho et al. (2006) avaliaram o efeito da temperatura ambiente para frangos de 42 a 49 dias de idade e verificaram que as temperaturas de 20 e $25^{\circ} \mathrm{C}$ não afetaram negativamente $\mathrm{o}$ desempenho e melhoraram a eficiência de retenção de nitrogênio, consequentemente, com menor excreção que aves a $32^{\circ} \mathrm{C}$. O pior balanço de nitrogênio para aves em estresse por calor é em função da menor eficiência de retenção de nitrogênio, como encontrado por Faria Filho et al. (2007) e Temim et al. (1999).

Tabela 5. Desdobramento da interação entre fase de criação e temperatura ambiente para o coeficiente de metabolizabilidade verdadeiro do nitrogênio (CMNV) em gramas da dieta-teste, para frangos de corte

\begin{tabular}{lccc}
\hline & \multicolumn{3}{c}{ Temperatura ambiente } \\
\cline { 2 - 4 } Fase & Fria & Termoneutra & Quente \\
\hline Inicial & $42,86 \mathrm{Ab}$ & $44,84 \mathrm{Ab}$ & $42,30 \mathrm{Aa}$ \\
Crescimento & $57,12 \mathrm{Aa}$ & $55,68 \mathrm{Aa}$ & $45,98 \mathrm{Ba}$ \\
Final & $44,30 \mathrm{Cb}$ & $55,85 \mathrm{Aa}$ & $50,05 \mathrm{Ba}$ \\
\hline
\end{tabular}

Médias seguidas por letras maiúsculas diferentes na linha e letras minúsculas diferentes na coluna diferem entre si $(\mathrm{P}<0,05)$ pelo teste de Tukey.

Houve diferença no CMNV entre as fases de criação na câmara fria e na termoneutra, não diferindo na câmara quente. Aves na fase de crescimento em estresse por frio apresentaram melhor metabolização do nitrogênio $(\mathrm{P}<0,05)$, e em temperatura termoneutra não diferiram da fase final. Pode-se perceber que a idade da ave não somente interfere nos valores 
de energia metabolizável, mas também na metabolizabilidade dos nutrientes da dieta.

Os resultados obtidos neste trabalho proporcionaram algumas conclusões. A energia metabolizável do farelo de soja não foi influenciada pela temperatura ambiente neste experimento, porém os valores de EMAn encontrados, 2110, 2016 e $2022 \mathrm{kcal} / \mathrm{kg}$ para temperatura fria, termoneutra e quente, respectivamente, foram mais baixos que o valor apresentado na tabela de Rostagno et al. (2005), de $2256 \mathrm{kcal} / \mathrm{kg}$, valor utilizado atualmente na formulação de dietas. Este resultado demonstra a necessidade de se ajustar estes valores de energia metabolizável do farelo de soja que hoje se apresentam superestimados.

A influência da idade do frango de corte sobre a utilização dos nutrientes foi bem demonstrada nos resultados deste trabalho, sendo assim, a idade deve ser considerada pelo nutricionista no momento da formulação da ração. $O$ valor de energia metabolizável do farelo de soja (EMAn) aumentou com o avanço da idade, 1840, 2052 e $2256 \mathrm{kcal} / \mathrm{kg}$ para as fases inicial, crescimento e final, respectivamente, sendo que, para as fases inicial e crescimento, os valores de EMAn foram mais baixos que o apresentado na tabela de Rostagno et al. (2005), de $2256 \mathrm{kcal} / \mathrm{kg}$, mostrando novamente a necessidade de se ajustar esses valores, para melhor adequar às exigências nutricionais do frango de corte.

\section{CONCLUSÕES}

Os valores médios de EMAn do farelo de soja, em $\mathrm{kcal} / \mathrm{kg}$, na matéria natural, para aves criadas em temperatura fria, termoneutra e quente, são de 2110, 2016 e 2022, respectivamente, e para as fases de criação inicial, crescimento e final, de 1840,2052 e 2256, respectivamente. O valor de energia metabolizável do farelo de soja, os balanços e os coeficientes de metabolizabilidade dos nutrientes da dieta-teste aumentam com a idade do frango de corte, porém não são afetados pela temperatura ambiente.

\section{AGRADECIMENTOS}

Os autores agradecem o apoio da Fundação de Amparo a Pesquisa do Estado de São Paulo FAPESP, por fornecer subsídios para a realização da pesquisa.

\section{REFERÊNCIAS BIBLIOGRÁFICAS}

BELLAVER, C.; SNIZEK Jr., P.N. Processamento da soja e suas implicações na alimentação de suínos e aves. In: CONGRESSO BRASILEIRO DE SOJA, 1999, Londrina, PR. Anais... Londrina, PR: EMBRAPA, 1999. p.183-199.

BONNET, S.; GERAERT, P.A.; LESSIRE, M. et al. Effect of high ambient temperature on feed digestibility in broiler. Poult. Sci., v.76, p.857-863, 1997.

DALE, N. Formulando com soya sobreprocesada. Ind. Avic., v.44, p.52-53, 1997.

FARIA FILHO, D.E. Aspectos produtivos, metabólicos, econômicos e ambientais da nutrição proteica para frangos expostos ao calor. 2006. $73 \mathrm{f}$. Tese (Doutorado em Zootecnia) - Faculdade de Ciências Agrárias e Veterinárias, Universidade Estadual Paulista, Jaboticabal, SP.

FARIA FILHO, D.E.; ROSA, O.S.; FIGUEIREDO, D.F. et al. Dietas de baixa proteína no desempenho de frangos criados em diferentes temperaturas. Pesq. Agropec. Bras., v.41, p.101-106, 2006.

FARIA FILHO, D.E.; CAMPOS, D.M.B.; AFONSOTORRES, K.A. et al. Protein levels for heat-exposed broilers: performance, nutrient digestibility, and protein and energy metabolism. Int. J. Poult. Sci., v.6, p.187-194, 2007.

FREITAS, E.R.; SAKOMURA, N.K.; NEME, R. et $a l$. Efeito do processamento da soja integral sobre a energia metabolizável e a digestibilidade dos aminoácidos para aves. Res. Bras. Zootec., v.34, p.1938-1949, 2005.

FURLAN, R.L; CARVALHO, N.C; MALHEIROS, E.B. et al. Efeito da restrição alimentar inicial e da temperatura ambiente sobre o desenvolvimento de vísceras e ganho compensatório em frangos de corte. Arq. Bras. Med. Vet. Zootec., v.53, p.492-498, 2001.

GENEROSO, R.A.R.; GOMES, P.C.; ROSTAGNO, H.S. et al. Composição química e energética de alguns alimentos para frangos de corte em duas idades. Res. Bras. Zootec., v.37, p.1251-1256, 2008.

GERAERT, P.A.; GUILLAUMIN, S.; ZUPRIZAL, L.M. Effect of high ambient temperature on dietary ME value in genetically lean and fat chickens. Poult. Sci., v.71, p.2113-2116, 1992.

KATO, K.R. Energia metabolizável de alguns ingredientes para frangos de corte em diferentes idades. 2005. 96f. Tese (Doutorado em Zootecnia) Departamento de Zootecnia, Universidade Federal de Lavras, Lavras, MG. 
KESHAVARZ, K.; FULLER, H.L. The influence of widely fluctuating temperatures on heat production and energetic efficiency of broilers. Poult. Sci., v.59, p.2121-2128, 1980.

MARCHINI, C.F.P.; SILVA, P.L; NASCIMENTO, M.R.B.M. et al. Morfometria da mucosa duodenal em frangos de corte submetidos à temperatura ambiente cíclica elevada. Arq. Bras. Med. Vet. Zootec., v.61, p.491-497, 2009.

MATTERSON, L.D.; POTTER, L.M.; STUTZ, N.W. et al. The metabolizable energy of feeds ingredients for chickens. Storrs: University of Connecticut, 1965. p.11.

McLEOD, M. Effects of amino acid balance and energy: protein ratio on energy and nitrogen metabolism in male broiler chicken. Br. Poult. Sci., v.38, p.405-411, 1997.

MELLO, H.H.C.; GOMES, P.C.; ROSTAGNO, H.S. et al. Valores de energia metabolizável de alguns alimentos obtidos com aves de diferentes idades. Res. Bras. Zootec., v.38, p.863-868, 2009.

NASCIMENTO, A.H.; GOMES, P.C.; ALBINO, L.F.T. et al. Valores de composição química e energética de alimentos para frangos de corte. Res. Bras. Zootec., v.27, p.579-583, 1998.

NOY, Y.; SKLAN, D. Posthatch development of poultry. J. Appl. Poult. Res., v.6, p.344-354, 1997.

OLIVEIRA, R.F.M.; ZANUSSO, J.T.; DONZELE, J.L. et al. Níveis de energia metabolizável para frangos de corte de 1 a 21 dias de idade mantidos em ambiente de alta temperatura. Rev. Bras. Zootec., v.29, p.810-816, 2000

PIVA, G.H. Efeito da forma física da ração para frangos de corte criados em diferentes temperaturas. 2008. 44f. Dissertação (Mestrado em zootecnia) Faculdade de Ciências Agrárias e Veterinárias, Universidade Estadual Paulista, Jaboticabal, SP.

PENZ Jr., A.M.; BRUNO, D.; FIGUEIREDO, A. Nutrição de frangos - Mudanças de paradigmas para o futuro. In: CONFERÊNCIA APINCO DE CIÊNCIAS E TECNOLOGIA AVÍCOLA, 21., 2009. Porto Alegre, Anais... Rio Grande do Sul: Facta, 2009. p.301-315.
ROSTAGNO, H.S.; ALBINO, L.F.T.; DONZELE, J.L. et al. Tabelas brasileiras para aves e suínos: composição de alimentos e exigências nutricionais. Viçosa: UFV, 2005. 185p.

RUTZ, F. Proteínas:Digestão e absorção. In: MACARI, M.; FURLAN, R.L.; GONZALES, E. (Eds.). Fisiologia aviária: aplicada a frangos de corte. Jaboticabal: FUNEP; 2002. 375p.

SAKOMURA, N.K.; DEL BIANCHI, M.; PIZAURO Jr., J.M. et al. Efeito da idade dos frangos de corte na atividade enzimática e digestibilidade dos nutrientes do farelo de soja e da soja integral. Rev. Bras. Zootec., v.33, p.924-935, 2004.

SAKOMURA, N.K.; ROSTAGNO, H.S. Métodos de pesquisa em nutrição de monogástricos. Jaboticabal: Funep, 2007. 283 p.

SILVA, D.J.; QUEIROZ, A.C. Análise de alimentos: métodos químicos e biológicos. Viçosa, MG: UFV, 2002. 235p.

SISTEMA de análises estatísticas e genéticas - SAEG. Viçosa: UFV, 2007. 140p.

TEMIM, S.; CHAGNEAU, A.M.; GUILLAUMIN, S. Effects of chronic heat exposure and protein intake on growth performance, nitrogen retention and muscle development in broiler chickens. Reprod. Nutr. Dev., v.39, p.145-156, 1999.

UNI. Z.; GANOT, S.; SKLAN, D. Posthatch development of mucosal function in the broiler small intestine. Poult. Sci., v.77, p.77-82, 1998.

YAMAZAKI, M.; ZI-YI, Z. A note on the effect of temperature on true and apparent metabolizable energy values of a layer diet. Br. Poult. Sci., v.23, p.447-450, 1982.

ZONTA, M.C.; RODRIGUES, P.B.; ZONTA, A. et al. Energia metabolizável de ingredientes proteicos determinada pelo método de coleta total e por equações de predição. Cienc. Agrotec., v.28, p.14001407, 2004.

ZUPRIZAL, M.L.; CHAGNEAU, A.M.; GERAERT, P.A. Influence of ambient temperature on true digestibility of protein and amino acid of rapeseed and soybean meals in broilers. Poult. Sci., v.72, p.289-295, 1993. 